\title{
¿DEBEMOS CREER TODAVÍA EN ELENA G. DE WHITE?- PRIMERA PARTE
}

\author{
Miguel A. Salomón \\ Universidad Peruana Unión \\ miguelsalomon@teologia.edu.pe
}

Fecha de recepción: Marzo 2014

Fecha de aceptación y versión final: Junio 2014

Entre los Adventistas del Séptimo Día, existe un sector que manifiesta cierto escepticismo, o abriga dudas, en aceptar a Elena G. de White como depositaria del don profético. Inclusive, hay quienes han rechazado y combatido ese ministerio profético, y lo continúan haciendo hasta hoy por diferentes medios, quizás por ignorancia sobre el contenido y el valor de sus escritos. Sin embargo, una lectura objetiva del ministerio del don de profecía en el seno de la denominación, evidencia el valor incalculable, en el surgimiento, desarrollo y consolidación del pueblo remanente. Este trabajo, hace referencia al aporte del don de profecía en el adventismo, con el propósito de confirmar la creencia y confianza en su conducción.

Palabras claves: Elena G. de White, don de profecia, iglesia remanente, movimiento adventista. 


\section{DO WE STILL BELIEVE IN ELLEN G. WHITE? PART ONE}

\section{Summary:}

Among Seventh-day Adventists, there is a sector that expresses some skepticism or doubts, to accept Ellen White as depository of the prophetic gift. Even some have rejected and fought that prophetic ministry, and continue to do this until now by various ways, perhaps out of ignorance about the content and value of his writings. However, an objective reading of the gift of prophecy ministry, within the denomination, can give invaluable evidence about his role in the emergence, development and consolidation of the remnant people. This work refers to the contribution of the gift of prophecy into of Adventism, with the purpose of confirming the belief and confidence in his driving.

Keywords: Ellen G. White, prophecy, remnant church, Adventist movement. 


\section{Introducción}

Durante los primeros años de ministerio, reconocer a un miembro de iglesia muy radical en sus apreciaciones, no aceptaba el don de profecía, aunque tenía varios años de militancia. Su molestia se acentuaba cuando se citaba alguna frase o pensamiento del don profético. Así como este caso, desde los inicios del movimiento adventista, han existido, existen ahora, y seguramente existirán, quienes muestran su descontento con la creencia en Elena G. de White como receptora del don de profecía. Y no solamente eso, hay quienes además de rechazar esta creencia, la combaten, y hasta ridiculizan a la Iglesia Adventista del Séptimo Día por aceptar el don de profecía, poniendo en tela de juicio su existencia como el pueblo remanente.

Pese a ello, una de las creencias distintivas con las que nació la Iglesia Adventista del Séptimo Día, fue precisamente el don de profecía, manifestado en la persona de Elena Harmon, (posteriormente, Elena G. de White, por su matrimonio en 1846). ${ }^{1}$ Hoy, esta creencia sigue en vigencia entre el pueblo adventista, y constituye parte de su plataforma teológica y su cuerpo de doctrinas. ${ }^{2}$ Es más, esta creencia se la considera como una señal distintiva de la iglesia adventista, y "una permanente y autorizada fuente de verdad, que proporciona consuelo, dirección, instrucción y corrección a la iglesia" ${ }^{3}$

Esto se hace evidente al repasar la historia de la denominación, donde se observa con claridad y certeza, la forma en que Dios empleó a esta dama, para conducir al pueblo adventista, hecho que sin duda ayuda a confirmar la creencia del don profético en la Iglesia Adventista del Séptimo Día. En el espacio que disponemos, veremos sólo algunos ejemplos que señalan algunos de los beneficios y ben-

1 George R. Knight, Nuestra iglesia, momentos históricos decisivos (Impreso en EE. UU., por Review and Herald, 2007), 38.

2 Asociación Ministerial de la Asociación General de la Iglesia Adventista del Séptimo Día, Creencias de los adventistas del séptimo día (Buenos Aires: Asociación Casa Editora Sudamericana, 2007), 246.

3 Ibíd. 
diciones que ha reportado el ministerio profético de la Sra. Elena G. de White en el pueblo de Dios.

Conduciendo la ubicación y organización de la iglesia

Son sorprendentes los resultados del ministerio de Elena $\mathrm{G}$. de White en los inicios del movimiento adventista, en cuanto a la organización se refiere. Sus sabios y oportunos consejos guiadores sobre la necesidad e importancia de organizarse como denominación, sentaron las bases de lo que hoy se conoce como la Iglesia Adventista del Séptimo Día. Sin duda alguna, este sistema de organización, ha contribuido en el crecimiento de este movimiento en toda la tierra.

Los historiadores de la denominación señalan que después del chasco de 1844, la gente se dispersó, quedó un número reducido que apenas llegaba a 30 . No existía un líder que dirigiera el movimiento. En principio estaban solamente los esposos White, José Bates, Crossier, Edson, Storrs, y algunos otros. Tampoco existía la voluntad de organizarse, ni disponían de recursos económicos para afrontar los gastos. Además, eran un grupo confesionalmente heterogéneo, de procedencia bautista, metodista, presbiteriano ${ }^{4}$, etc.

Es más, no conseguían ponerse de acuerdo en cuanto a la organización, por el contrario, resistían todo intento en esta dirección. Influenciados por Charles Fitch, quien sostenía que había que salir de las iglesias protestantes a quienes las consideraba como Babilonia. Quien más se oponía a todo intento de organización fue George Storrs, quien afirmó que "ninguna iglesia puede organizarse por la invención del hombre que no llegue a ser Babilonia en el momento que se organiza". ${ }^{5}$ Esta posición sin duda revelaba la antipatía hacia

4 Ver: George Knight, Nuestra organización, ¿Aliada o enemiga de la gran comisión? (Florida: Asociación Publicadora Interamericana, 2007), 26-31.

5 Emma E. Howell, El gran movimiento adventista (Buenos Aires: Asociación Casa Editora Sudamericana, s.f.), 52; Richard W. Schwarz y Floyd Greenleaf, Portadores de luz (Buenos Aires: Asociación Casa Editora Sudamericana, 2000), 83. 
las iglesias organizadas que los habían despedido, y tildaban a la Iglesia Católica como Babilonia y a las denominaciones protestantes como sus hijas. Es más, no se disponía de un sistema para remunerar a los pastores, cada uno actuaba independientemente y no existía un sistema de control. Los templos y algún patrimonio que se adquiría, figuraban a nombre de personas particulares, con el riesgo que ello implicaba. Además, no tenían un lugar definido de residencia, porque deambulaban por diferentes ciudades de tres estados del Este de Norteamérica, los estados de Nueva Inglaterra, Connecticut y Nueva York. Para completar esta caótica situación, este nuevo movimiento religioso carecía de un nombre que los identificara dentro del concierto de denominaciones religiosas de los Estados Unidos, y que les proporcionara una razón social, mediante una personalidad jurídica.

Finalmente, en 1855, por instrucción profética, se trasladaron a Batlle Creek, estado de
Michigan, para establecerse con objetivos bien definidos, para lograr el desarrollo del movimiento. En esas circunstancias, Elena G. de White aconsejó: "La carga de la obra está en el Oeste y es de mayor importancia que los hombres, siervos de Dios, avancen donde su providencia les abra el camino". ${ }^{6}$ De esta manera, gracias a su nueva ubicación, la denominación se extendió rápidamente a los territorios del Oeste y el Canadá. Para esta fecha, más de la tercera parte de los guardadores del sábado procedían del sector occidental, y constituyó un gran paso para la extensión del adventismo en la mayoría de los estados del Oeste?

\section{La necesidad de organizar- se (1853)}

A una década de producido el chasco, el grupo sentía la imperiosa necesidad de una organización formal, pero al parecer

6 Elena G. de White, Testimonies for the Church (Mountain View, CA: Pacific Press Publishing Association, 1948), 149.

7 Arturo G. Daniels, El permanente don de profecía (Buenos Aires: Asociación Casa Editora Sudamericana, 1962), 405. 
resonaba todavía el eco de Storrs, que había calado profundamente y su influencia provocaba la oposición a tales iniciativas. Más adelante, en 1853, J. White escribió cinco editoriales en la Review and Herald sobre la necesidad de contar con una organización, sin obtener respuesta positiva; su esposa finalmente urgió a los miembros adventistas para dar los pasos necesarios en torno al inicio de la organización. ${ }^{8}$ Los primeros pasos no fueron fáciles. Elena comentó lo que sucedió en aquel tiempo: "[...] había en nuestro pueblo violenta animosidad contra la organización -luego añade- Hubimos de sostener dura lucha para instituir la organización". 9 Pese a ello, y luego de varios consejos, como el que había dado, después de recibir una visión en septiembre de 1853, escribió:

El Señor ha mostrado que el orden evangélico ha sido temido y

8 Herbert E. Douglas, Mensajera del Señor (Buenos Aires: Asociación Casa Editora Sudamericana, 2000), 184.

9 Elena G. de White, Testimonios selectos vol. 1 (Buenos Aires: Asociación Casa Editora Sudamericana, s.f.), 193. descuidado en demasía. Debe rehuirse el formalismo; pero al hacerlo, no se debe descuidar el orden. Hay orden en el cielo. Había orden en la iglesia cuando Cristo estaba en la tierra, y después de su partida el orden fue estrictamente observado entre sus apóstoles. $\mathrm{Y}$ ahora en estos postreros días, mientras Dios está llevando a sus hijos a la unidad de la fe, hay más necesidad real de orden que nunca antes, porque, a medida que Dios une a sus hijos, Satanás y sus malos ángeles están muy atareados para evitar esta unidad y para destruirla [...] De esta manera la causa de Dios sufre oprobio, y la verdad es rehuida por muchos incrédulos $[\ldots]^{10}$

Luego añadió, "La iglesia debe recurrir a la Palabra de Dios y establecerse en el orden evangélico, que ha sido pasado por alto y descuidado". ${ }^{11}$ Otro consejo llegó con las siguientes palabras: "Hay orden en el cielo, y a Dios le agradan los esfuerzos de su pueblo al procurar obrar con sistema y orden en la tierra. Y vi que debe haber orden en la

10 Elena G. de White, Primeros escritos (Mountain View, CA: Publicaciones Interamericanas, 1967), 97.

11 Ibíd., 100. 
iglesia de Dios, y que es necesario un sistema para llevar adelante con éxito el último gran mensaje de misericordia al mundo". ${ }^{2}$

Pasado el tiempo, y después de mucha discusión, finalmente el movimiento adventista logró dar los pasos necesarios para elegir un nombre, y organizar las primeras unidades eclesiásticas administrativas, como la Asociación Publicadora de los Adventistas del Séptimo Día, realizada el 3 de mayo de 1961. Luego la Asociación de Michigan (5 de octubre de 1861), a la que le siguieron otras. Finalmente, se dio

el paso trascendental de crear la Asociación General, realizada entre el 20 y 23 de mayo de 1863. Para esta fecha, los adventistas sumaban 3,500 miembros, agrupados en los estados del Nor Este de Estados Unidos. ${ }^{13} \mathrm{La}$ misma profetisa ponderó los beneficios y resultados de la organización con estas palabras:

12 Elena G. de White, Testimonies for the Church, vol. 1 (Mountain View, CA: Pacific Press Publishing Association, 1948), 191.

13 Richard W. Schwarz y Floyd Greenleaf, Portadores de luz, 91-94.
A medida que nuestros miembros fueron aumentando, resultó evidente que sin alguna forma de organización habría gran confusión, y la obra no se realizaría con éxito. Para proporcionar sostén al ministerio, para dirigir la obra en nuevos territorios, para proteger tanto a las iglesias como a los ministros de los miembros indignos, para custodiar las propiedades de la iglesia, para la publicación de la verdad por medio de la prensa, y para muchos otros objetos, la organización era indispensable. ${ }^{14}$

Con la nueva organización la Iglesia logró un avance significativo. Se añadieron nuevos miembros, diversos territorios fueron alcanzados, y se crearon nuevas asociaciones, luego se establecieron distintas instituciones como el colegio de Battle Creek en 1874, el sanatorio en el mismo lugar en 1866, la Casa de Publicaciones y la sede de la Asociación General. Arturo G. Daniels, ${ }^{15}$ presidente de la Asociación General, al evaluar el

14 ElenaG.deWhite,Testimoniospara los ministros (Buenos Aires: Asociación Casa Editora Sudamericana, 1961), 22.

15 Arturo G. Daniels, El permanente don de profecía, 351. 
sistema de organización adventista, señaló que era, "amplia, práctica y eficiente”, indicando que se basaba en los principios de organización del AT y NT.

\section{La reorganización y el Congreso de la Asociación General de 1901}

Después de 38 años de existencia, el adventismo atravesaba una situación caótica administrativamente hablando, y al decir de un historiador de la iglesia: "la denominación se acercaba al borde de la bancarrota", ${ }^{16}$ esto hizo necesaria la oportuna orientación de Elena G. de White. Su participación se realizó en el contexto de una crisis de carácter administrativo a las puertas del Congreso de 1901. Los problemas administrativos se los ha descrito de esta manera: En primer lugar, había una concentración de instituciones en Battle Creek, que se constituía en la "meca" de los adventistas, que impedía el crecimiento de la

16 George Knigth, Nuestra organización, ¿Aliada o enemiga de la gran comisión?, 116. iglesia en otras regiones, tanto dentro como fuera de los Estados Unidos. En segundo lugar, las decisiones que se tomaban para atender los asuntos importantes en las diferentes regiones del mundo estaba en manos de muy pocas personas, y cuando se las tomaba, desde Battle Creek, se hacía con desconocimiento de la realidad distante, y muchas veces no eran las más acertadas, demorando el desarrollo de la misión. También, hay que considerar que la feligresía de la iglesia en ese año, se conformaba de 73,499 miembros, y el $23 \%$ de la feligresía se encontraba fuera de Estados Unidos. ${ }^{17}$ En tercer lugar, había unidades administrativas independientes que funcionaban como súper estructuras autónomas y representadas por corporaciones. El sector de salud estaba en manos de La Asociación Internacional de Obra Misionera Médica y de Benevolencia, la Escuela Sabática estaba dirigida por La Asociación Internacional de Escuela

17 http://docs.adventistarchives. org//doc_info.asp?DocID=118944 (Consultado: 09 de abril de 2014). 
Sabática, la acción misionera era dirigida por La Sociedad Internacional de Tratados, y para promover la libertad religiosa estaba La Asociación Nacional de Libertad Religiosa. En cuarto lugar, tanto la Asociación General, la Junta de Misiones Extranjeras y la Asociación Internacional de Obra Misionera Médica y de Benevolencia, enviaban misioneros provocando confusión y competencia. Finalmente, entre otras cosas, se añadía a esta confusa administración, la falta de planificación del presupuesto

y el manejo provocaba susceptibilidades porque no cubría los compromisos financieros de la organización. ${ }^{18}$

De esta manera, la iglesia mundial fue convocada para un congreso donde se esperaban

18 Ellen G. White State, Notas y escritos concernientes a Elena G. de White y el Espíritu de Profecía, 133. Los fondos disponibles en caja llegaban solamente a 32,93 dólares y que habían sido obtenidos a préstamo. Además, la deuda acumulada de las instituciones adventistas, dependientes de la Asociación General, alcanzaban la fabulosa cantidad para esa época, de "un millón y cuarto de dólares” Ver: George Knigth, 116; Richard W. Schwarz y Floyd Greenleaf, Portadores de luz, 246-257. que ocurriesen cambios substanciales. La crónica denominacional cuenta que al parecer, nadie sabía cómo enfrentar esa crisis administrativa. En su informe inaugural y después de repasar los eventos más importantes de su gestión, Guillermo Irwin, presidente de la Asociación General, en aquella época finalizó diciendo: "El nuestro es un momento trascendental y esta es una ocasión trascendental. No hay sabiduría humana suficiente para hacer planes y trazar los proyectos que se necesitan hacer" ${ }^{19}$ Irwin tenía razón, si no hubiese sido la clara y directa orientación divina, a través de su sierva, quien sabe qué rumbo se hubiese tomado.

Previa a la inauguración del congreso, Elena G. de White se reunió con los 13 miembros de la Junta Directiva de la Asociación General y los principales representantes de las instituciones adventistas. Les había comunicado las instrucciones divinas recibidas y la necesidad urgente de

19 Ellen G. White State, Notas y escritos concernientes a Elena G. de White y el Espíritu de Profecía, 133. 
introducir una reorganización. Era evidente, que el Conductor del pueblo remanente, mediante su sierva, estaba indicando la necesidad de realizar una "cirugía mayor" a la organización existente. Lo que siguió, es narrado de la siguiente forma:

Cuando el presidente se sentó, la sierva de Dios se puso de pie e inició una alocución muy solemne, algunas de sus palabras fueron estas: ¿Por qué os pregunto, se permite que hombres que no se han sometido a sí mismos, ocupen puestos importantes en la verdad y manejen las cosas sagradas?... Los principios del cielo deben practicarse en cada familia, en la disciplina de cada iglesia, en cada establecimiento, en cada institución, en cada escuela y en todo lo que deba ser manejado. No tenéis derecho de dirigir a menos que lo hagáis según el orden que Dios establece. ¿Estáis sometidos a la dirección de Dios? ¿Veis vuestra responsabilidad para con él?". 20

Después de nueve años de permanencia en Australia, la Sra. White retornó a casa. La ad-

20 Ibíd., 134. ministración de la iglesia atravesaba una seria crisis. Al parecer, todos esperaban la introducción de cambios en el sistema administrativo.

Al concluir su mensaje, Elena G. de White instó a reorganizar la iglesia y los asistentes apoyaron en forma unánime la iniciativa. Los planes trazados con anterioridad para ese congreso se dejaron a un lado y se puso en marcha el proceso de reorganización. Luego de varias sugerencias y propuestas, finalmente, se nombró una Junta Consultiva integrada por 75 miembros encargada de dirigir todo el proceso. Esta junta se encargó de nombrar comisiones tales como la de Publicaciones, Obra Misionera, Comisión de Organización y otras. Esta última fue la que más trabajo realizó, cada día presentaba informes que eran aprobados por el plenario en medio de la admiración. Los principales cambios a realizarse estaban los siguientes:

1. Formar uniones en todo el territorio de Norteamérica, siguiendo el modelo de Australia. 
2. Que la Asociación General esté integrada por representantes de las diferentes instituciones de la iglesia.

3. Que la Junta Directiva de la Asociación General tome el lugar de las juntas y comisiones.

4. Que la Junta Directiva de la Asociación General esté compuesta por 25 miembros.

5. Que los presidentes de uniones sean parte integrante de la junta.

Cuando todo el informe estaba para ser votado, pareció bloquearse por un momento y se temió que el congreso sería un fracaso. Finalmente, después de la intervención de Elena G. de White, todo el paquete fue votado, con esto se dio inicio a una nueva etapa en la organización. Luego se procedió a la organización de las uniones y al nombramiento de sus administradores y a la redacción de sus estatutos. ${ }^{21}$ Después de tres semanas de arduo trabajo, el 23 de abril de 1901, se dio por concluido este histórico congreso, considerado con razón como el

21 Ibid. más importante de la Iglesia Adventista, con la satisfacción de haber hecho lo que Dios había indicado a través de su sierva. ${ }^{22}$ Se había democratizado la administración, la centralización fue corregida y se logró la delegación de responsabilidades, confiando el trabajo en el mayor número de personas. ${ }^{23}$ Elena G. de White de regreso a su hogar llena de regocijo escribió: "Durante el Congreso General, el Señor obró maravillosamente a favor de su pueblo. Cada vez que pienso en aquella reunión me inunda una dulce solemnidad y un sentimiento de gratitud embarga mi alma. Hemos visto las pisadas de nuestro Señor y Redentor. Alabemos su santo nombre porque él ha obrado la liberación de su pueblo". ${ }^{24}$

\section{Ibíd.}

23 Bert Haloviak, de la Oficina de Archivos y Estadística 2007, "Informe sobre la Historia Organizacional de los Adventistas del Séptimo Día" (un trabajo en proceso), en: http://www.adventistarchives.org/documents.asp? CatID $=4 \&$ SortBy $=0 \&$ ShowDateOrder $=$ True (Consultado: 22 de octubre de 2008)

24 Ellen G. White State, Notas y escritos concernientes a Elena G. de White y el Espíritu de Profecía, 140. 


\section{El Congreso de 1903}

El año siguiente del histórico congreso de 1901, dos acontecimientos lamentables habían ocurrido para los adventistas. El gigantesco sanatorio y la casa editora fueron consumidos por las llamas de dos voraces incendios en Battle Creek. La sierva de Dios en reiteradas ocasiones había aconsejado sobre la necesidad de salir de allí, pero su voz no fue escuchada.

$\mathrm{Al}$ iniciarse el congreso en Oakland, California, en 1903, una de las primeras propuestas fue el traslado de la sede de la Asociación General y de la casa editora. Pese a las voces de rechazo a esta decisión tomada, por la firme insistencia de Elena G. de White, el traslado debía realizarse de todos modos. Cuando los dirigentes estaban perplejos sobre la elección del lugar, y aunque se inclinaban por la ciudad de Nueva York, la mensajera del Señor les escribió diciendo que pensaran en trasladarse a Washington, porque cualquier lugar que estuviese a menos de $50 \mathrm{ki}$ - lómetros de Nueva York, estaría demasiado cerca. Después de sortear distintos obstáculos, la capital de los Estados Unidos se convirtió en la sede de la iglesia adventista y la casa editora. El último número de la Review and Herald fue impreso el 11 de agosto en Battle Creek, el siguiente número salió el jueves de la siguiente semana en Washington. Mediante este medio oficial los hermanos se enteraron del acuerdo final y de los pormenores del traslado. Nuevamente al seguirse el consejo inspirado, se vio la mano divina dirigiendo a su iglesia. ${ }^{25}$

Los testimonios son abundantes e inspiradores de quienes han visto y experimentado la forma como Dios ha conducido a este movimiento a través de los años. Debemos permanecer adheridos a los testimonios del don profético para estar seguros de la conducción divina, en nuestras vidas y en la iglesia.

25 Arturo G. Daniells, El permanente don de profecía, 408-411. 